\title{
The Natural Occurrence of Two Distinct Begomoviruses Associated with DNA $\beta$ and a Recombinant DNA in a Tomato Plant from Indonesia
}

\author{
Tatsuya Kon, Sri H. Hidayat, Shu Hase, Hideki Takahashi, and Masato Ikegami
}

\begin{abstract}
First, third, fourth, and fifth authors: Department of Life Science, Graduate School of Agricultural Science, Tohoku University, 1-1 Tsutsumidori-Amamiyamachi, Aoba-ku, Sendai 981-8555, Japan; and second author: Department of Plant Pests and Diseases, Faculty of Agriculture, Bogor Agricultural University, Bogor 16680, Indonesia.
\end{abstract}

Accepted for publication 6 January 2006.

\begin{abstract}
Kon, T., Hidayat, S. H., Hase, S., Takahashi, H., and Ikegami, M. 2006. The natural occurrence of two distinct begomoviruses associated with DNA $\beta$ and a recombinant DNA in a tomato plant from Indonesia. Phytopathology 96:517-525.

Two begomoviruses (Java virus-1 and Java virus-2), two satellite DNAs (DNAB01 and DNAB02), and a recombinant DNA (recDNA) were cloned from a single tomato plant from Indonesia with leaf curl symptoms, and the role of these satellite DNAs in the etiology of begomovirus disease was investigated. The genome organizations of the two viruses were similar to those of other Old World monopartite begomoviruses.

Comparison of the sequences with other begomoviruses revealed that Java virus-1 was a newly described virus for which the name Tomato leaf curl Java virus (ToLCJAV) is proposed. Java virus-2 was a strain of Ageratum yellow vein virus (AYVV) (AYVV-[Java]). ToLCJAV or AYVV-[Java] alone did not induce leaf curl symptoms in tomato plants. However, in the presence of DNA $\beta 02$, both ToLCJAV and AYVV-[Java] induced leaf curl symptoms in tomato plants. In the presence of DNA 01 , these viruses induced mild leaf curl symptoms in tomato plants. The recDNA had a chimeric sequence, which arose from recombination among ToLCJAV, AYVV-[Java], DNA $\beta 01$, and DNA $\beta 02$; it was replicated only in the presence of AYVV-[Java] in tomato plants.
\end{abstract}

Geminiviruses have monopartite or bipartite circular singlestranded DNA (ssDNA) genomes, encapsidated in geminate particles. The family Geminiviridae consists of four genera, distinguished according to their host range, insect vector, and genome organization (11). The majority of the family Geminiviridae belong to the genus Begomovirus, which is transmitted by the whitefly (Bemisia tabaci). Tomato leaf curl diseases have caused losses in tomato production throughout the world (36), and many viruses causing leaf curl disease in tomato have been characterized $(9,10,15,19,24,32)$. For example, Tomato leaf curl New Delhi virus-Severe (ToLCNDV-Svr) (24) has a bipartite genome consisting of two circular ssDNA molecules (DNA-A and DNAB), whereas Tomato leaf curl virus (ToLCV) (9), Tomato leaf curl Bangalore virus (ToLCBV) (15), Tobacco leaf curl Japan virus (TbLCJV) (32), and Tomato leaf curl Philippines virus (ToLCPV) (19) are monopartite. Several distinct begomoviruses have been associated with tomato leaf curl in Indonesia (34).

Recently, satellite DNAs associated with several monopartite begomoviruses have been reported $(3,5,16,27,28,37)$. Furthermore, infectious clones of the monopartite begomoviruses Ageratum yellow vein virus (AYVV) from Singapore, Cotton leaf curl Multan virus (CLCuMV) from Pakistan, Bhendi yellow vein mosaic virus (BYVMV) from India, Tomato yellow leaf curl China virus-[Tobacco Y10] (TYLCCNV-[Tb:Y10]), and Eupatorium yellow vein virus (EpYVV) were unable to induce typical symptoms. A novel group of satellite DNA molecules called

Corresponding author: M. Ikegami; E-mail address: ikegami@bios.tohoku.ac.jp

The DDBJ, EMBL, and GenBank accession numbers of the sequences reported in this paper are AB100304 (ToLCJAV), AB100305 (AYVV-[Java]), AB100306 (DNA $\beta 01), A B 113651$ (DNAß02), and AB116230 (recombinant DNA).

DOI: 10.1094/PHYTO-96-0517

(C) 2006 The American Phytopathological Society
DNA $\beta$, which are associated with these viruses, is essential for inducing the characteristic disease symptoms $(5,16,27,28,37)$. DNA $\beta$ is approximately half the size of the genomic DNA, and except for a conserved hairpin structure and a TAATATTAC loop sequence, has little sequence similarity with the genomic DNA of the associated begomovirus. DNA $\beta$ requires a helper begomovirus DNA for replication, encapsidation, insect transmission, and movement in plants (27).

In this paper, we identify and characterize two distinct begomoviruses, two satellite DNA $\beta$ s, and a recombinant DNA from a single tomato plant with leaf curl symptoms from Indonesia. One begomovirus is newly described and is called Tomato leaf curl Java virus (ToLCJAV), whereas the other is a strain of AYVV[Java]. Both satellite DNA $\beta$ s (DNA $\beta 01$ and DNA $\beta 02)$ replicated in the presence of either ToLCJAV or AYVV-[Java]. The recombinant DNA had a chimeric genome with sequences of begomovirus genomic DNA and satellite DNA $\beta$.

\section{MATERIALS AND METHODS}

Cloning of full-length viral genomic DNA. Tomato plants showing leaf curl symptoms were collected from Bandung, West Java, Indonesia. Nucleic acids were extracted from the leaf tissues of infected tomato plants, as described by Kon et al. (19). The polymerase chain reaction (PCR) was carried out as described by Sharma et al. (31).

Initially, a 2.7-kbp viral DNA PCR product was obtained using begomovirus DNA-specific degenerate primers UPV1 and UPC2 (6) and cloned into pGEM-T Easy vector (Promega, Madison, WI). Clones with two different sequences were obtained and designated Java virus-1 and Java virus-2. Two primers with an $X b a \mathrm{I}$ site (underlined), ToXba1 (5'-TCTAGACACGATGTTAGTCACGTGGG-3') and ToXba2 (5'-TCTAGACTCAAAAGACTGGACCTTAC- $3^{\prime}$ ), were designed to obtain a full-length clone 
of Java virus-1 (pToX1). Two primers with a BamHI site (underlined), ToBam1 (5'-GGATCCTCTTTTGAACGAGTTTC-3') and ToBam2 (5'-GGATCCCACATTTCTTTAATTTC-3'), were designed to obtain a full-length clone of Java virus-2 (pToB1).

Two methods were used in an attempt to detect a DNA-B component in virus-infected tomato plants. In the first method, PCR with CRv1 (5'-TAATATTACCGGATGGCCGC-3') and CRc2 (5'-AAAAAATTATGCCA-3') was designed to amplify near full-length DNA fragments representing the genome component(s) of the begomoviruses with an intergenic region (IR)/ common region (CR) sequence with similarity to Java virus-1 and Java virus-2. The PCR-amplified viral genomic DNA was digested using restriction endonucleases BamHI, EcoRI, HindIII, SalI, NcoI, and NdeI. In the second method, PCR detection of DNA-B was carried out using DNA-specific degenerate primers PCRc1 (5'-CTAGCTGCAGCATATTTACRARWATGCCA-3'; R = $\mathrm{A}, \mathrm{G} ; \mathrm{W}=\mathrm{A}, \mathrm{T})$ and PBL1v2040 (5'-GCCTCTGCAGCARTGRTCKATCTTCATACA-3'; $\mathrm{K}=\mathrm{G}, \mathrm{T} ; \mathrm{R}=\mathrm{A}, \mathrm{G})$ (25).

Cloning of full-length satellite DNA $\beta s$, and satellite-like DNA. Initially, a 1.4-kbp DNA $\beta$ fragment was amplified using PCR and primers Beta01 and Beta02 designed for CLCuMV DNA $\beta$ (4). The PCR-amplified fragment was cloned in pGEM-T Easy vector and sequenced. Two different clones were obtained and designated DNA $\beta 01$ and DNA $\beta 02$. Primers StCla1 (5'-ATCGATGAATCTTTATACATGATCC- $\left.3^{\prime}\right)$ and StCla2 (5'-ATCGATCGAGGAGATCAAAGCAGAAG-3') were both designed with a ClaI site (underlined) to obtain full-length clones pTo $\beta 01$ (DNA $\beta 01)$ and pToß02 (DNA $\beta 02)$.

Initially, a $0.8-\mathrm{kbp}$ satellite-like DNA fragment was amplified using primers V3518 and 3996 designed for AYVV recDNA (27). The PCR-amplified fragment was cloned in pGEM-T Easy vector and sequenced. Primers StBamH1 (5'-GGATCCTCTTTTGAACGAGTTTCCTG-3') and StBamH2 (5'-GGATCCCACATGTTAAAATAATACTTGG-3') were both designed with a BamHI site (underlined) to obtain a full-length clone of satellite-like DNA (pToR1).

Sequence analysis. Sequencing was performed as described by Kon et al. (18) and the complete nucleotide sequences were compared with those of other monopartite begomoviruses or the DNA-A of bipartite begomoviruses. Phylogenetic analyses comparing Java virus-1, Java virus-2, open reading frame (ORF) V1 (coat protein $[\mathrm{CP}]$ ), ORF $\mathrm{C} 1$ (replication associated protein: Rep), DNA $\beta 01$, or DNA $\beta 02$ sequences to other begomovirus sequences available from GenBank were computed from a distance matrix made using Kimura's two-parameter method. Multiple sequence alignments were performed using the optimal alignment method of DNAsis software. Phylogenetic trees were generated using the neighbor-joining method of MEGA version 3.0 with 1,000 bootstrap replications (20).

The detection of potential sequences, identification of likely parent sequences, and localization of possible recombination break points were carried out using RDP version 2.0 (22). To search for

A

pBToX1.4
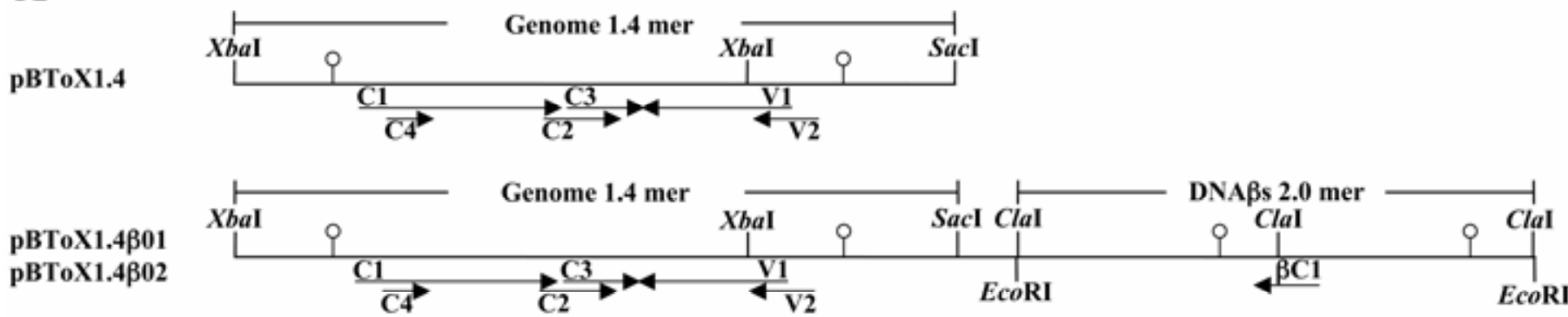

pBToX1.4Rec

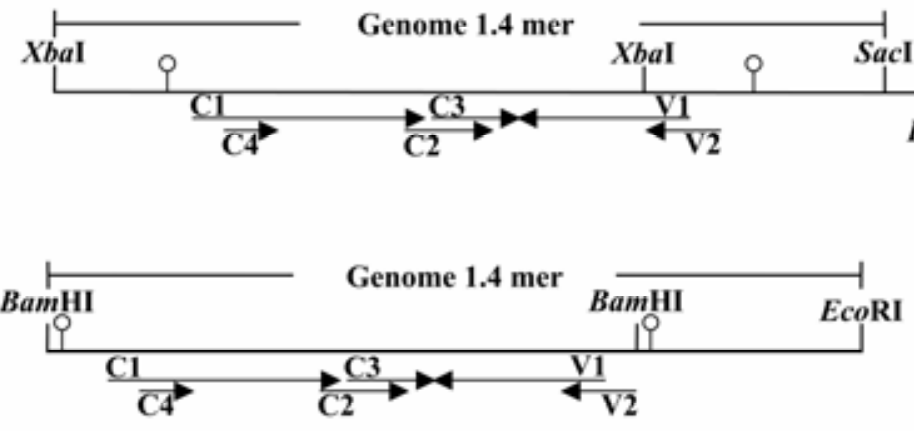

pBToB1.4

B

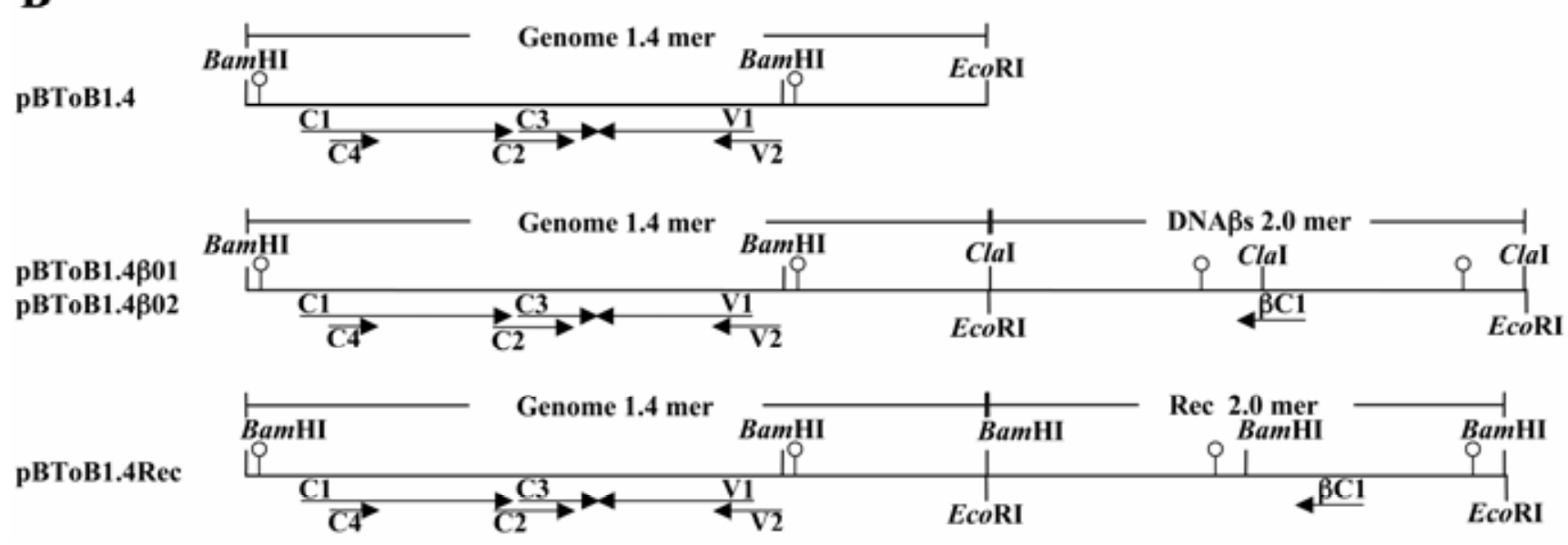

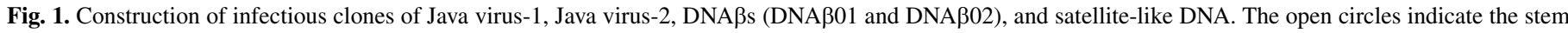

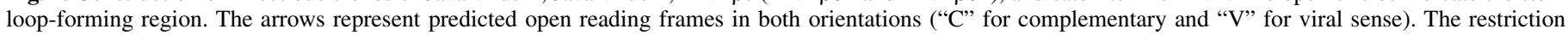

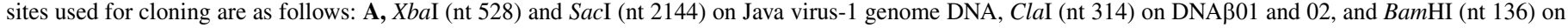

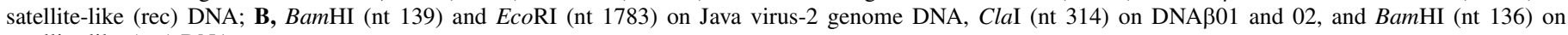
satellite-like (rec) DNA. 
recombination events, the RDP settings used were multiple comparison correction off, internal reference selection, highest acceptable probability 0.0001 , and a window size of 10 .

Constructing infectious clones and agroinoculation. Standard methods were used to produce the following clones containing partial and tandem repeats in pBI121 (Clontech, Palo Alto, CA) (Fig. 1): 1.4-mer of Java virus-1 (pBToX1.4), 1.4-mer of Java virus-2 (pBToB1.4), 1.4-mer of Java virus-1 + 2.0-mer of DNA $\beta 01$ (pBToX1.4 301 ), 1.4-mer of Java virus-1 + 2.0-mer of DNA $\beta 02$ (pBToX1.4 $\beta 02$ ), 1.4-mer of Java virus- $2+2.0$-mer of DNA $\beta 01$ (pBToB1.4 301 ), 1.4-mer of Java virus- $2+2.0$-mer of DNA $\beta 02$ (pBToB1.4 $\beta 02$ ), 1.4-mer of Java virus-1 + 2.0-mer of satellite-like DNA (pBToX1.4Rec), and 1.4-mer of Java virus-2 + 2.0-mer of satellite-like DNA (pBToX1.4Rec).

These recombinant plasmids were mobilized from Escherichia coli DH5 $\alpha$ cells into Agrobacterium tumefaciens LBA4404 (14) by triparental mating using E. coli HB101 containing the helper plasmid pRK2013 (8). Tomato (Lycopersicon esculentum cv. Hausumomotaro) and Nicotiana benthamiana were used for agroinoculation experiments. Agroinoculation was performed as described by Kon et al. (18). Viral DNA was detected by PCR using viral genomic DNA-, DNA $\beta$-, and satellite-like DNA-specific primers.

\section{RESULTS}

Genome organization of Java virus-1, Java virus-2, satellite DNA $\beta$ s, and satellite-like DNA. The complete Java virus- 1 and Java virus-2 genomes consisted of 2,752 and 2,735 nucleotides, respectively (accession nos. AB100304 and AB100305). The genome organizations of these viruses were similar to those of other monopartite begomoviruses originating from the Old World (Fig. 2). A 33-base potential stem loop-forming region was identical in the IRs of both viruses. In contrast, the iteron or Rep high-affinity binding site differed in Java virus-1 and Java virus-2. The Java virus-1 iteron was GGTCTCAA (nucleotides 2617 to 2624 and 2651 to 2659), whereas that of Java virus-2 was GGAGACA (nucleotides 2615 to 2621,2642 to 2648 , and 2649 to 2655). Efforts to detect DNA-B components associated with Java virus-1 and Java virus-2 based on restriction fragment length polymorphism analysis or PCR using primers PCRc1 and PBL1v2040 were unsuccessful. From these results, we concluded that Java virus- 1 and Java virus- 2 are monopartite begomoviruses.

DNA $\beta 01$ and DNA $\beta 02$ consisted of 1,346 and 1,354 nucleotides, respectively (accession nos. AB100306 and AB113651, respectively). Each DNA $\beta$ contained one complementary-sense ORF ( $\beta C 1$ ) (Fig. 2). DNA $\beta 01$ and DNA $\beta 02$ had no obvious sequence homology with the Java virus-1 or Java virus-2 genomic DNA, except for the nonanucleotide sequence TAATATT/AC. The sequences of DNA $\beta 01$ and DNA $\beta 02$ contained an A-rich region ( $\approx 65 \%$ ) between nucleotides 736 to 941 and 721 to 950 , respectively. The putative replication associated protein-binding motifs present in Java virus-1 (GGTCTCAA) and Java virus-2 (GGAGACA) were not found in DNA $\beta 01$ or DNA $\beta 02$, but similar sequences were located upstream from the stem loop structure: GGTGTGTA (nucleotides 1260 to 1267 , DNA $\beta 01$ : nucleotides 1268 to 1275 , DNA $\beta 02$ ), GGTAGAAA (nucleotides 1278 to 1285, DNA $\beta 01$ : nucleotides 1286 to 1293, DNA $\beta 02$ ), and GGAGAAG (nucleotides 1210 to 1216, DNA $\beta 01$ : nucleotides 1218 to 1224 , DNA 302 ).

The nucleotide sequence of satellite-like DNA comprised 1,299 nucleotides (accession no. AB116230) and contained one complementary-sense ORF ( $\beta C 1)$ (Fig. 2). The region from nucleotides 1112 to 233 of satellite-like DNA had the highest sequence identity with the corresponding sequences of Java virus1 (nucleotides 2560 to 233: 82\%) and Java virus-2 (nucleotides 2560 to 236: 84\%). The satellite-like DNA sequence from nucleotides 367 to 1110 had the highest sequence identity with nucleo- tides 135 to 877 of DNA $\beta 01(86 \%)$ and nucleotides 135 to 879 of DNA 302 (94\%) (Fig. 2). The iteron (GGTCTCAA) present in Java virus-1 was not found in satellite-like DNA, whereas the iteron (GGAGACA) in Java virus-2 was found in satellite-like DNA (virus sense nucleotides 1167 to 1173,1194 to 1200 , and 1201 to 1207).

Sequence analysis of viral genomic DNA, DNA $\beta$, and satellite-like DNA. The complete nucleotide sequences of Java virus-1 and Java virus-2 were compared with those of other begomoviruses. Java virus-1 had nucleotide sequence identities with AYVV of $87 \%$ and Java virus- 2 of $85 \%$. For ORF V1 (CP), Java virus-1 had the highest amino acid sequence identities with its counterparts from AYVV (87\%), Tomato leaf curl Laos virus (ToLCLV) (87\%), and Java virus-2 (87\%). For ORF C1 (Rep), Java virus-1 had the highest amino acid sequence identities with its counterparts from AYVV (90\%) and Java virus-2 (86\%). Java virus-1 had nucleotide sequence IR identities with AYVV of $82 \%$ and Java virus- 2 of $73 \%$.

Java virus-2 had the highest total nucleotide sequence identity with AYVV (92\%). When the deduced amino acid sequence of the CP was compared, Java virus-2 had high amino acid sequence identity with its counterpart from AYVV (97\%). For Rep, Java virus-2 had the highest amino acid sequence identity with its counterparts from AYVV (93\%). Java virus-2 had a nucleotide sequence IR identity with AYVV of $75 \%$.

The phylogenetic tree based on comparison of the complete nucleotide sequence (DNA-A) showed that Java virus-2 clustered with Ageratum yellow vein Taiwan virus-[Taiwan] (AYVTV-[TW]), Ageratum yellow vein China virus-[Hainan 2] (AYVCNV-[Hn2]), and Java virus-1 (Fig. 3A). A similar relationship held when the $\mathrm{CP}$ sequence of Java virus-2 was analyzed (Fig. 4A). The phylogenetic analysis of the CP sequence revealed that Java virus-1 was distantly related to the ageratum-infecting begomovirus group (Fig. 4A). The phylogenetic tree based on comparison of the Rep sequences showed that Java virus-2 was similar to AYVV and clustered with ToLCPV, ToLCLV, and Java virus-1 (Fig. 4B). Fauquet and Stanley (11) proposed that a virus with less than $90 \%$
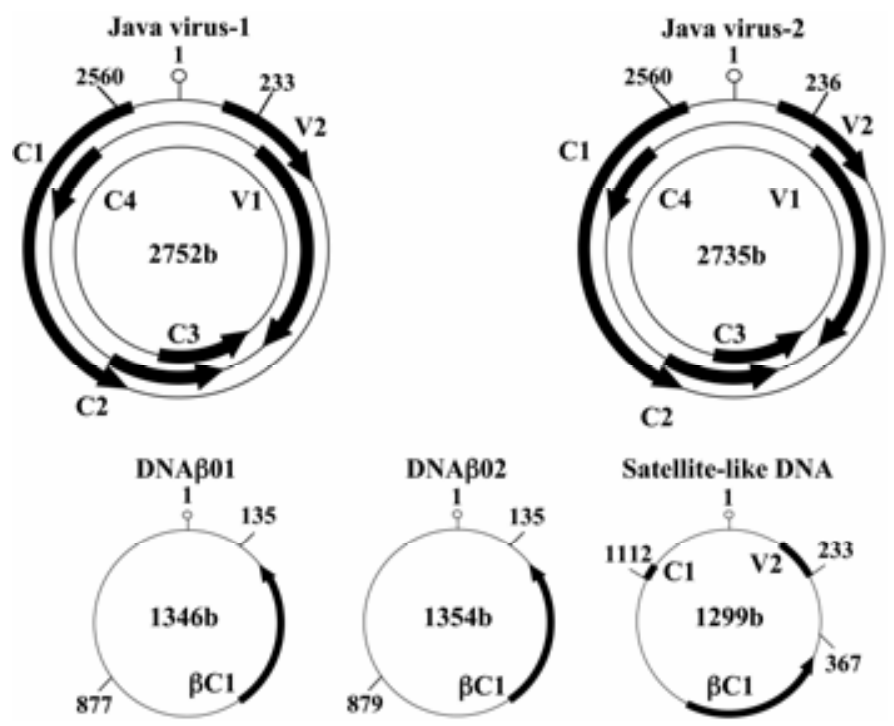

Fig. 2. The genome organizations of Java virus-1, Java virus-2, DNA $\beta$ s (DNA $\beta 01$ and DNA $\beta 02$ ), and satellite-like DNA. Open circles indicate the stem loop-forming region containing the conserved nonanucleotide TAATATT $\downarrow$ AC. Nucleotide numbering starts from the nick site $(\downarrow)$ within the conserved nonanucleotide. Arrows represent predicted open reading frames in both orientations ("C" for complementary and "V" for viral sense) and potentially encoded proteins are shown as black arrows. The region of satellitelike DNA from nt 1112 to 233 originates from Java virus-1 (nt 2560 to 233) and Java virus-2 (nt 2560 to 236) genomic DNAs. The sequences of the satellite-like DNA (nt 367 to 1112), DNAß01 (nt 135 to 877), and DNA 302 (nt 135 to 879 ) have high sequence identity. 
identity for the complete genome and $\mathrm{CP}$ sequences should be considered a distinct species. Therefore, Java virus-1 is proposed to be a new species: Tomato leaf curl Java virus (ToLCJAV), whereas Java virus-2 is a strain of AYVV, AYVV-[Java].

A phylogenetic tree was constructed from the alignment of the complete nucleotide sequences of DNA $\beta 01$, DNA $\beta 02$, and selected DNA $\beta$ s associated with other begomoviruses. DNA $\beta 01$ and DNA $\beta 02$ were similar to AYVV DNA $\beta$, but distantly related to other DNA $\beta$ s associated with other begomoviruses (Fig. 3B). The total nucleotide sequence of DNA $\beta 01$ had the highest identity $(93 \%)$ with that of DNA $\beta 02$, followed by AYVV DNA $\beta$ $(81 \%)$. The amino acid sequence of the $\beta C 1$ product of DNA $\beta 01$
A

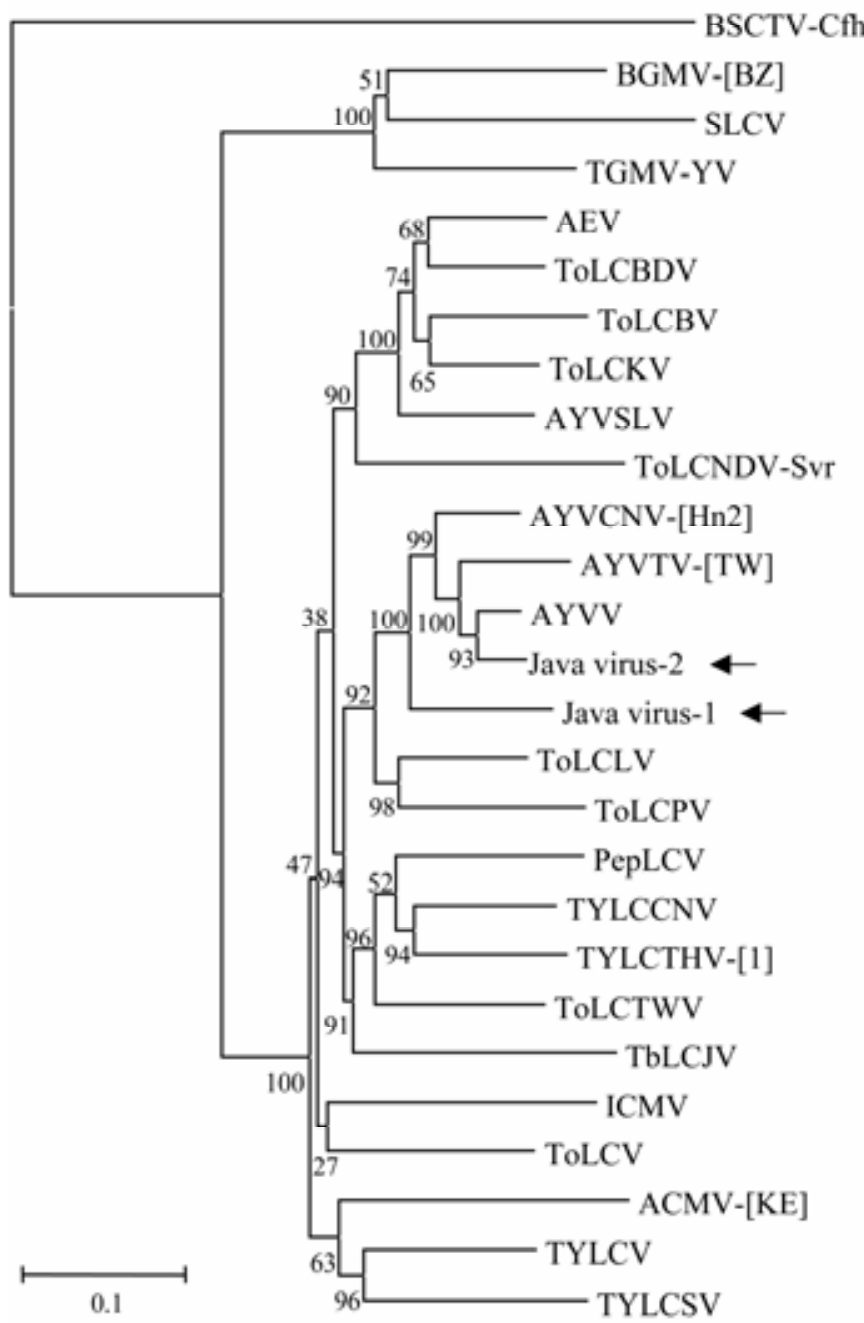

B

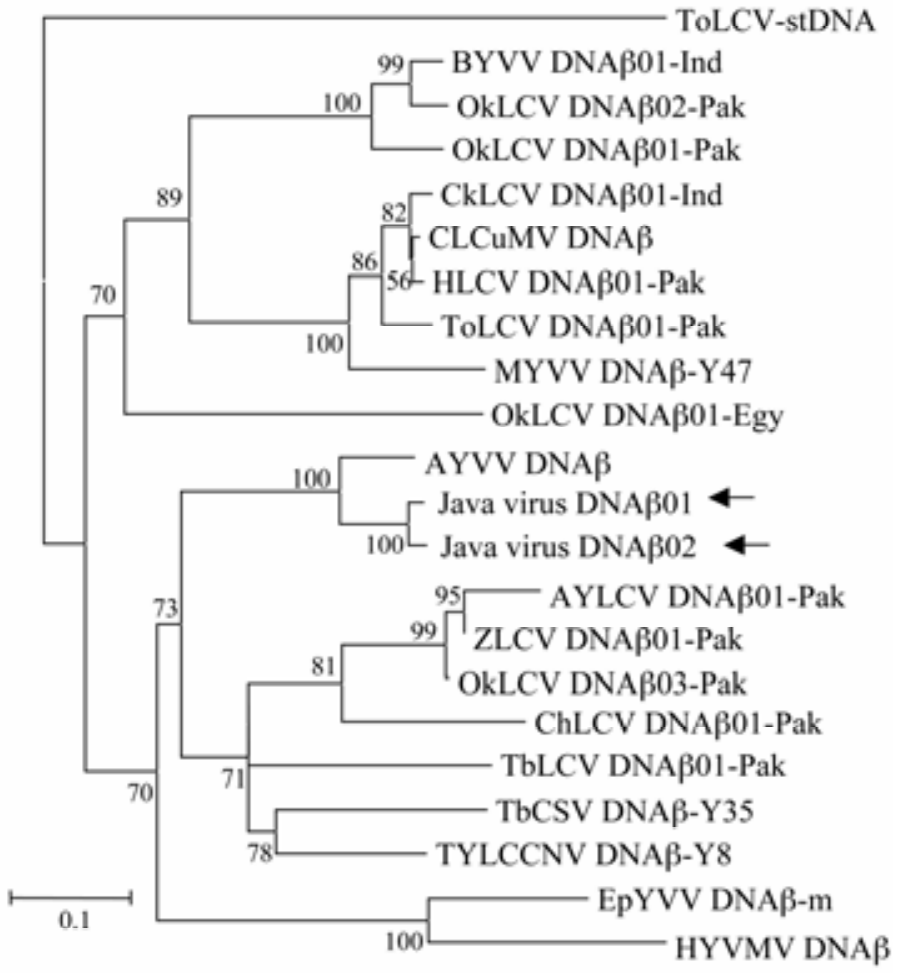

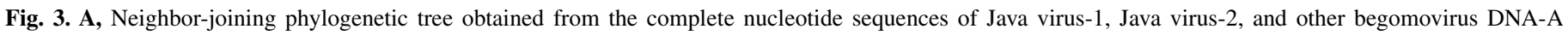

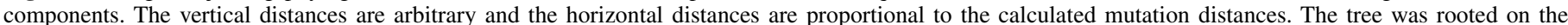

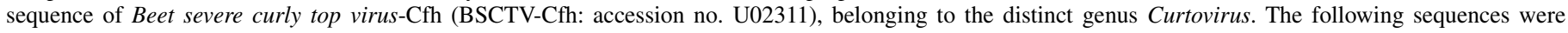

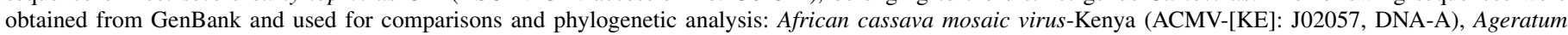

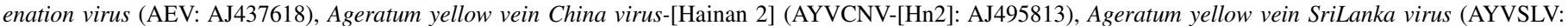

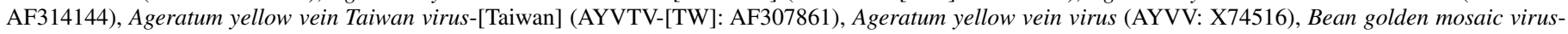

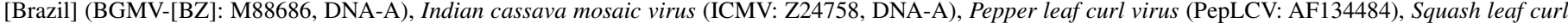

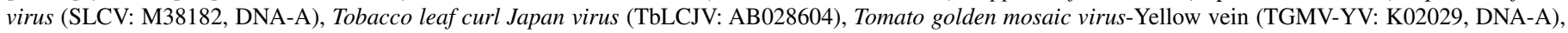

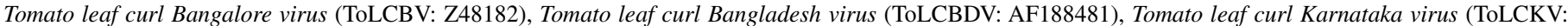

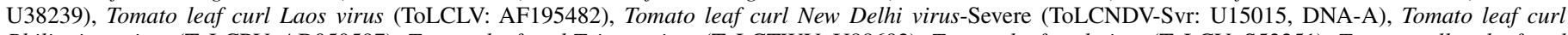

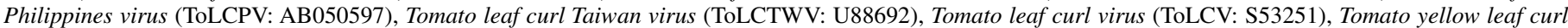

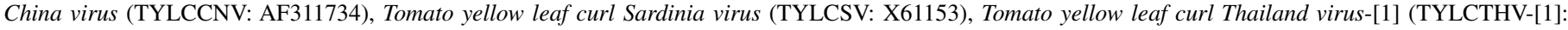

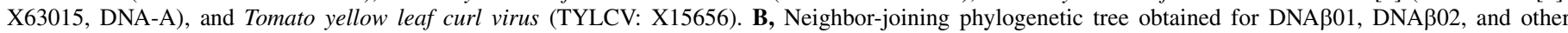

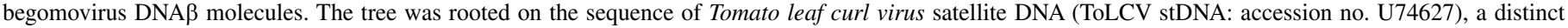

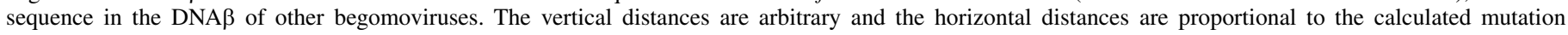

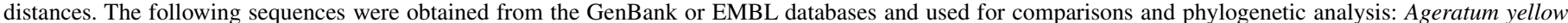

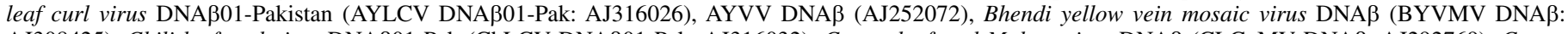

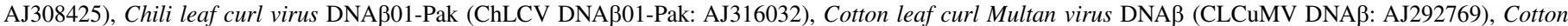

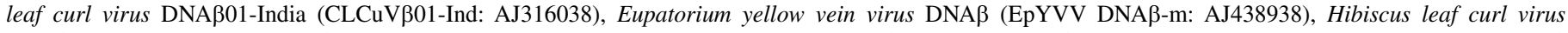

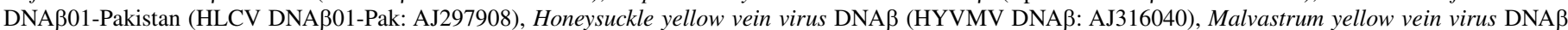

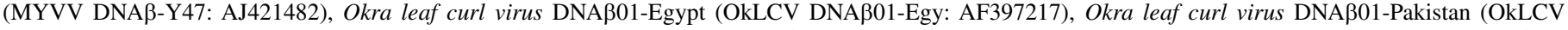

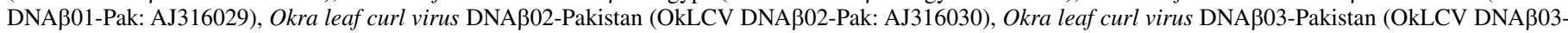

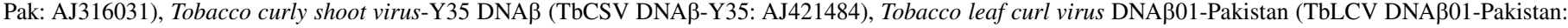

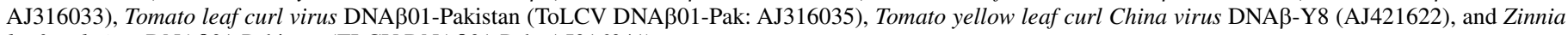
leaf curl virus DNAß01-Pakistan (ZLCV DNAß01-Pak: AJ316041). 
had the highest identity (89\%) with that of DNA $\beta 02$. The $\beta C 1$ products of DNA $\beta 01$ and DNA $\beta 02$ also had relatively high amino acid sequence identities (79 and $85 \%$, respectively) with that of AYVV DNA $\beta$.

We tested whether satellite-like DNA had a chimeric genome that arose from viral genomic DNA and satellite DNA using RDP. RDP provided evidence for the occurrence of recombination among ToLCJAV, AYVV-[Java], DNA $\beta 01$, and DNA $\beta 02$ (Fig. 5). In these recombination events, a region (nucleotides 1155 to 39) of recDNA corresponds to nucleotides 2633 to 43 of AYVV-[Java] genomic DNA $\left(P=2.870 \times 10^{-13}\right)$, which included the IR. Two regions (nucleotides 77 to 123 and 190 to 216 ) of recDNA also correspond to nucleotides 77 to 123 and nucleotides 190 to 216 of ToLCJAV genomic DNA $\left(P=2.580 \times 10^{-5}\right.$ and $3.670 \times 10^{-4}$, respectively). An additional two regions (nucleotides 367 to 883 and 450 to 1110 ) of recDNA correspond to nucleotides 135 to 652 of DNA $\beta 01\left(P=9.981 \times 10^{-5}\right)$ and nucleotides 219 to 879 of DNA $302\left(P=4.210 \times 10^{-9}\right)$, respectively. From these results, we concluded that satellite-like DNA had a chimeric genome that arose from recombination involving ToLCJAV, AYVV-[Java], DNA $\beta 01$, and DNA $\beta 02$, and was given the name recombinant DNA (recDNA).

Infectivity and symptoms induced by viral genomic DNA, DNA $\beta s$, and recDNA. The infectivity of ToLCJAV, AYVV[Java], DNA $\beta 01$, DNA $\beta 02$, and recDNA was examined in tomato and $N$. benthamiana (Table 1). Plants mock-agroinoculated with Agrobacterium cells with the empty binary vector did not develop symptoms (Fig. 6A). Tomato plants agroinoculated with ToLCJAV (clone pBToX1.4) were infected systemically, but displayed no symptoms (Fig. 6B). When tomato plants were co-agroinoculated with ToLCJAV and DNA $\beta 01$ (clone pBToX1.4 $\beta 01$ ), mild downward leaf curling symptoms were produced (Fig. 6G); whereas when tomato plants were co-agroinoculated with ToLCJAV and DNA $\beta 02$ (clone pBToX1.4 302 ), severe downward leaf curling symptoms developed (Fig. 6H). PCR detected ToLCJAV-, DNA $\beta 01-$, and DNA $\beta 02$-specific DNAs from agroinoculated tomato plants (Fig. 7A and B), and the PCR-amplified product was cloned and sequenced.

$N$. benthamiana plants agroinoculated with ToLCJAV developed mild downward leaf curling symptoms (Table 1). N. benthamiana plants co-agroinoculated with ToLCJAV and DNA $\beta 01$ developed mild downward leaf curling symptoms, whereas $N$. benthamiana plants co-agroinoculated with ToLCJAV and DNA $\beta 02$ developed severe downward leaf curling symptoms (Table 1).

Tomato plants agroinoculated with AYVV-[Java] (clone pBToB1.4) alone were infected systemically, but displayed no symptoms (Fig. 6C). Tomato plants co-agroinoculated with AYVV-[Java] and DNA $\beta 01$ (clone pBToB1.4 301 ) developed mild downward leaf curling (Fig. 6J), whereas tomato plants agroinoculated with AYVV-[Java] and DNA $\beta 02$ (clone pBToB1.4 $\beta 02$ )
$\mathbf{A}$

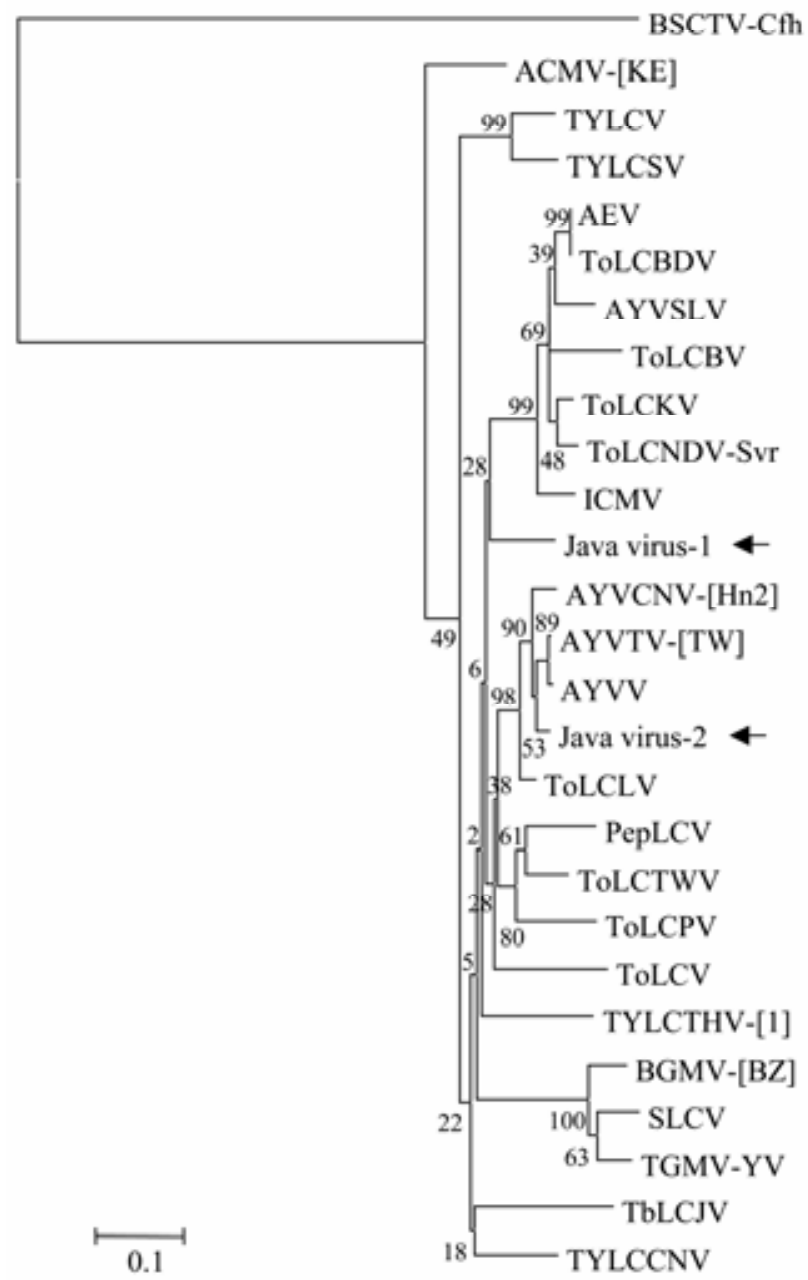

B

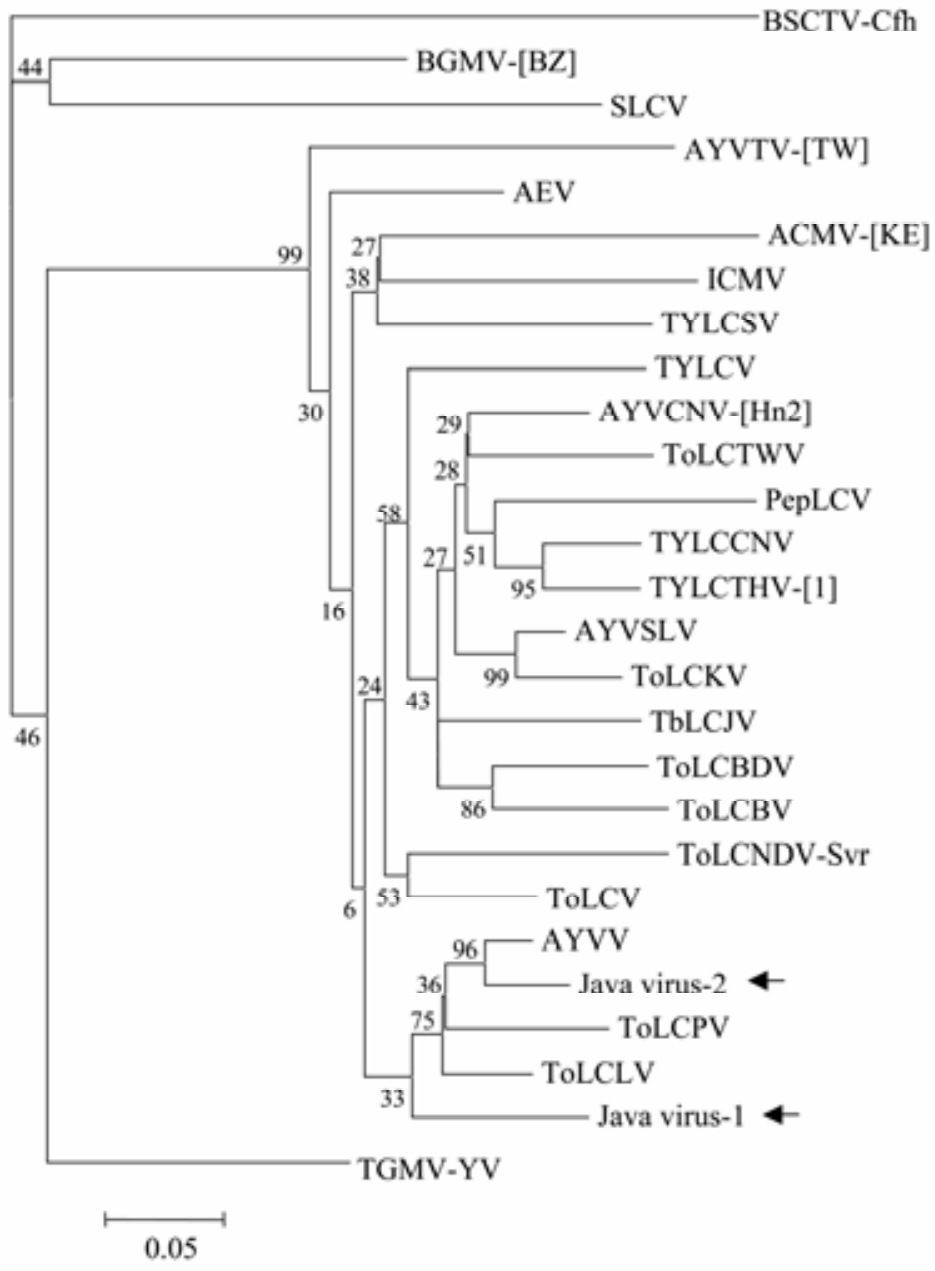

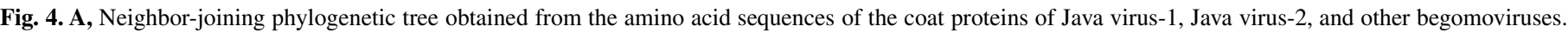

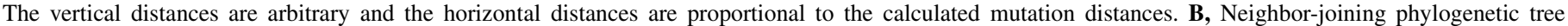

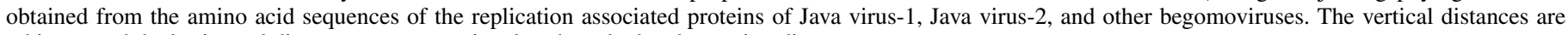
arbitrary and the horizontal distances are proportional to the calculated mutation distances. 
developed severe downward leaf curling (Fig. 6K). AYVV-[Java]-, DNA $\beta 01-$, and DNA $\beta 02$-specific DNAs were detected by PCR from agroinoculated tomato plants (Fig. 7A and B). No symptoms were observed on tomato plants agroinoculated with DNA $\beta 01$ or DNA 302 alone (Fig. 6D and E).

$N$. benthamiana plants agroinoculated with AYVV-[Java] developed severe upward leaf curling and vein swelling symptoms (Table 1). N. benthamiana plants co-agroinoculated with AYVV[Java] and DNA $\beta 01$ developed mild downward leaf curling symptoms, whereas $N$. benthamiana plants co-agroinoculated with AYVV-[Java] and DNA $\beta 02$ developed severe downward leaf curling symptoms (Table 1 ). Therefore, both DNA $\beta 01$ and DNA $\beta 02$ were replicated in the presence of either virus.

We tested whether recDNA is replicated by either ToLCJAV or AYVV-[Java]. Tomato plants co-agroinoculated with ToLCJAV and recDNA (clone pBToX1.4Rec) displayed no symptoms (Fig. 6I). ToLCJAV genomic DNA was detected in infected tomato plants, but not recDNA by PCR analysis (Fig. 7A and B). N. benthamiana plants co-agroinoculated with ToLCJAV and recDNA developed mild downward leaf curling symptoms (Table 1). Tomato plants co-agroinoculated with recDNA and AYVV-[Java] (clone pBToB1.4Rec) displayed no symptoms (Fig. 6L). However, both AYVV-[Java] genomic DNA and recDNA were detected in agroinoculated tomato plants by PCR analysis (Fig. 7A and B). No symptoms were observed in tomato plants agroinoculated with recDNA alone (Fig. 6F). N. benthamiana plants agroinoculated with AYVV-[Java] and recDNA developed severe upward leaf curling symptoms (Table 1).

When tomato plants were agroinoculated with ToLCJAV, AYVV-[Java], DNA $\beta 01$, DNA $\beta 02$, and recDNA, leaf curl symp-

\section{RecDNA \\ $1 / 1299 b$}

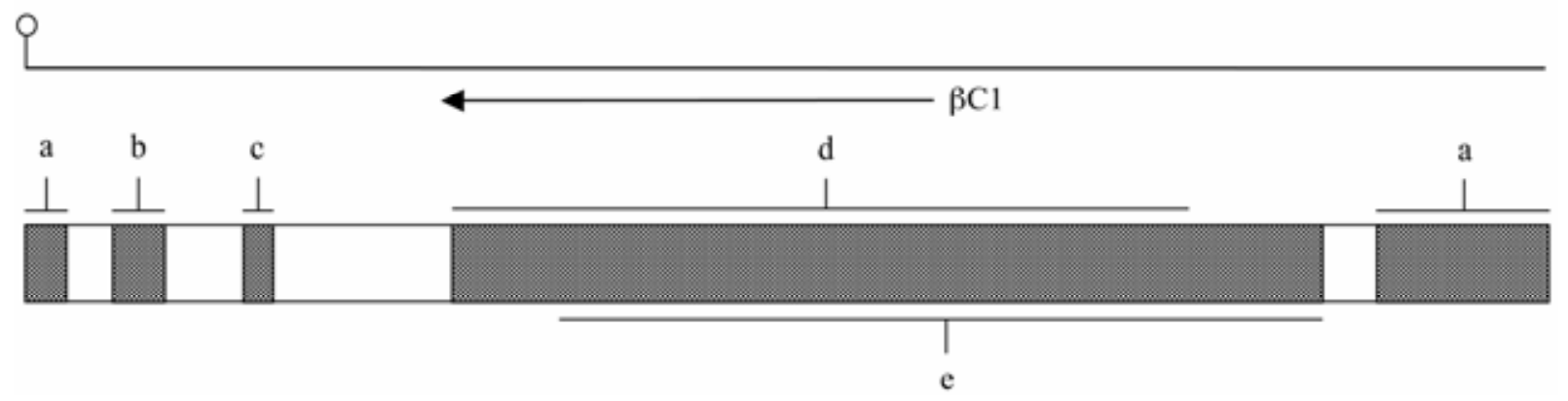

\begin{tabular}{|c|c|c|c|}
\hline Event & Region & Origin & $P$-value \\
\hline a & nt. $1153-39$ & AYVV-[Java] (nt. 2633-43) & $2.870 \times 10^{-13}$ \\
\hline b & nt. $\quad 77-123$ & ToLCJAV (nt. 81-129) & $2.580 \times 10^{-5}$ \\
\hline $\mathrm{c}$ & nt. $190-216$ & ToLCJAV (nt. 218-246) & $3.670 \times 10^{-4}$ \\
\hline d & nt. $367-883$ & DNAß01 (nt. 135-652) & $9.981 \times 10^{-5}$ \\
\hline $\mathrm{e}$ & nt. $450-1110$ & DNA 302 (nt. 219-879) & $4.210 \times 10^{-9}$ \\
\hline
\end{tabular}

Fig. 5. A schematic representation of the recombinant regions in satellite-like DNA. Potential recombination break points and the probability that the indicated regions do not have a recombination origin are presented. The shading patterns indicate the viral genomic DNA or satellite DNA $\beta$ origins of the recombinant region. The open circle indicates the stem loop-forming region. The $\beta \mathrm{C} 1$ open reading frame is indicated with an arrow.

TABLE 1. Symptom phenotypes of Tomato leaf curl Java virus (ToLCJAV), Ageratum yellow vein virus (AYVV-[Java]), DNA $\beta 01$, DNA 302 , and recDNA

\begin{tabular}{|c|c|c|c|}
\hline Plant & Inoculum $^{\mathrm{a}}$ & Infectivity ${ }^{\mathrm{b}}$ & Symptoms \\
\hline $\begin{array}{l}\text { Tomato } \\
\text { (Lycopersicon esculentum) } \\
\text { cv. Hausumomotaro }\end{array}$ & 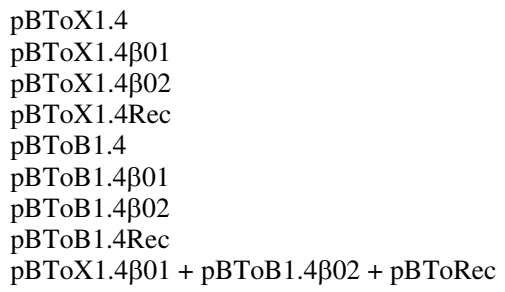 & $\begin{array}{l}19 / 24(3) \\
20 / 24(3) \\
23 / 24(3) \\
20 / 24(3) \\
20 / 24(3) \\
20 / 24(3) \\
23 / 24(3) \\
21 / 24(3) \\
25 / 32(4)\end{array}$ & $\begin{array}{l}\text { No symptoms } \\
\text { Mild downward leaf curling } \\
\text { Severe downward leaf curling } \\
\text { No symptoms } \\
\text { No symptoms } \\
\text { Mild downward leaf curling } \\
\text { Severe downward leaf curling } \\
\text { No symptoms } \\
\text { Severe downward leaf curling }\end{array}$ \\
\hline Nicotiana benthamiana & 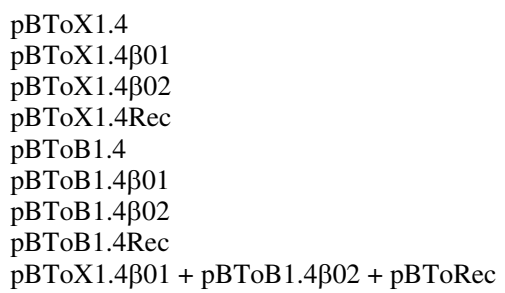 & $\begin{array}{l}14 / 15(3) \\
14 / 15(3) \\
15 / 15(3) \\
15 / 15(3) \\
15 / 15(3) \\
14 / 15(3) \\
15 / 15(3) \\
15 / 15(3) \\
23 / 25(4)\end{array}$ & $\begin{array}{l}\text { Mild downward leaf curling } \\
\text { Mild downward leaf curling } \\
\text { Severe downward leaf curling and stunting } \\
\text { Mild downward leaf curling } \\
\text { Severe upward leaf curling and vein swelling } \\
\text { Mild downward leaf curling } \\
\text { Severe downward leaf curling and stunting } \\
\text { Severe upward leaf curling and vein swelling } \\
\text { Severe downward leaf curling and stunting }\end{array}$ \\
\hline
\end{tabular}

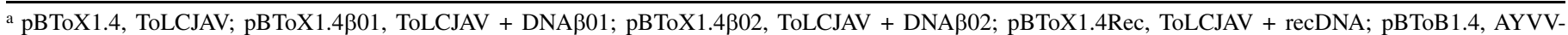

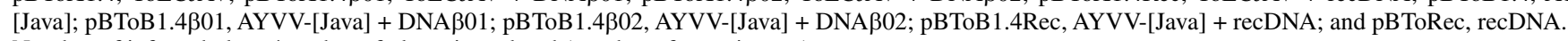

${ }^{\mathrm{b}}$ Number of infected plants/number of plants inoculated (number of experiments). 
toms developed and resembled the symptoms in tomato plants infected with ToLCJAV and DNA 302 or AYVV-[Java] and DNA 302 (Fig. 6M). The presence of viral genomic DNA, DNA $\beta$ s, and recDNA in agroinoculated plants was confirmed by PCR analysis (Fig. 7A and B).

\section{DISCUSSION}

In this study, we described the cloning, sequencing, phylogenetics, and biological activities of two distinct monopartite begomovirus species along with two associated satellite DNA $\beta$ s
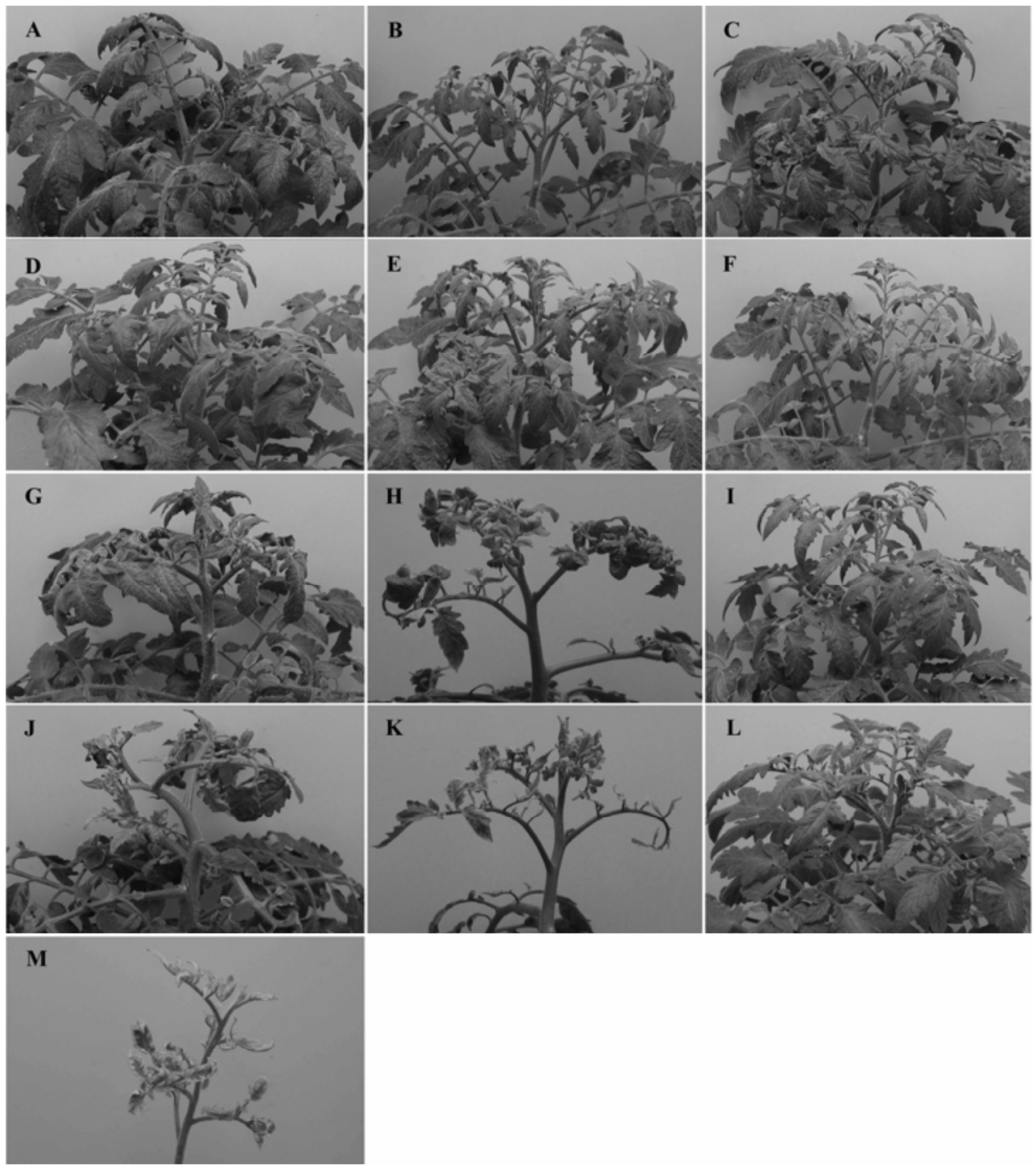

Fig. 6. Tomato plants inoculated with A, mock-agroinoculation, B, Tomato leaf curl Java virus (ToLCJAV) alone, C, Ageratum yellow vein virus (AYVV-[Java]) alone, D, DNA $\beta 01$ alone, E, DNA $\beta 02$ alone, $\mathbf{F}$, recDNA alone, G, ToLCJAV + DNA $\beta 01, \mathbf{H}$, ToLCJAV + DNA $\beta 02$, I, ToLCJAV + recDNA, J, AYVV-[Java] + DNA $\beta 01, \mathbf{K}$, AYVV-[Java] + DNA $\beta 02, \mathbf{L}$, AYVV-[Java] + recDNA, and M, ToLCJAV + AYVV-[Java] + DNA $\beta 01+$ DNA $\beta 02+$ recDNA. The plants were photographed 25 days postinoculation. 
as well as a recombinant defective DNA which combined sequences of a parent begomovirus and a DNA $\beta$ from tomato plants with leaf curl in Java, Indonesia. This is the first detailed analysis for Indonesia, extending earlier partial investigations of the same authors (34). Comparisons of the complete nucleotide sequences with other begomoviruses revealed that Java virus- 1 is a new species for which the name Tomato leaf curl Java virus (ToLCJAV) is proposed, whereas Java virus-2 was identified as a strain of AYVV, AYVV-[Java]. We previously reported that several begomoviruses are associated with tomato leaf curl disease in Java, Indonesia (34). Based on sequence comparisons and phylogenetic analyses, the viruses clustered into two groups. Group I was most closely related to AYVV-[Java] and group II had high sequence identity with ToLCJAV. The infectious clones of ToLCJAV or AYVV-[Java] alone did not induce leaf curl symptoms in tomato plants. By contrast, in the presence of DNA $\beta 02$, either ToLCJAV or AYVV-[Java] induced leaf curl symptoms in tomato plants. The leaf symptoms that DNA $\beta 02$ induced in agroinoculated tomato plants were similar to those observed in the field in Java, Indonesia. ToLCJAV/DNA $\beta 02$ and AYVV-[Java]/ DNA 302 may be tomato leaf curl disease complexes. Neither ToLCJAV nor AYVV-[Java] induced leaf curl symptoms in tomato
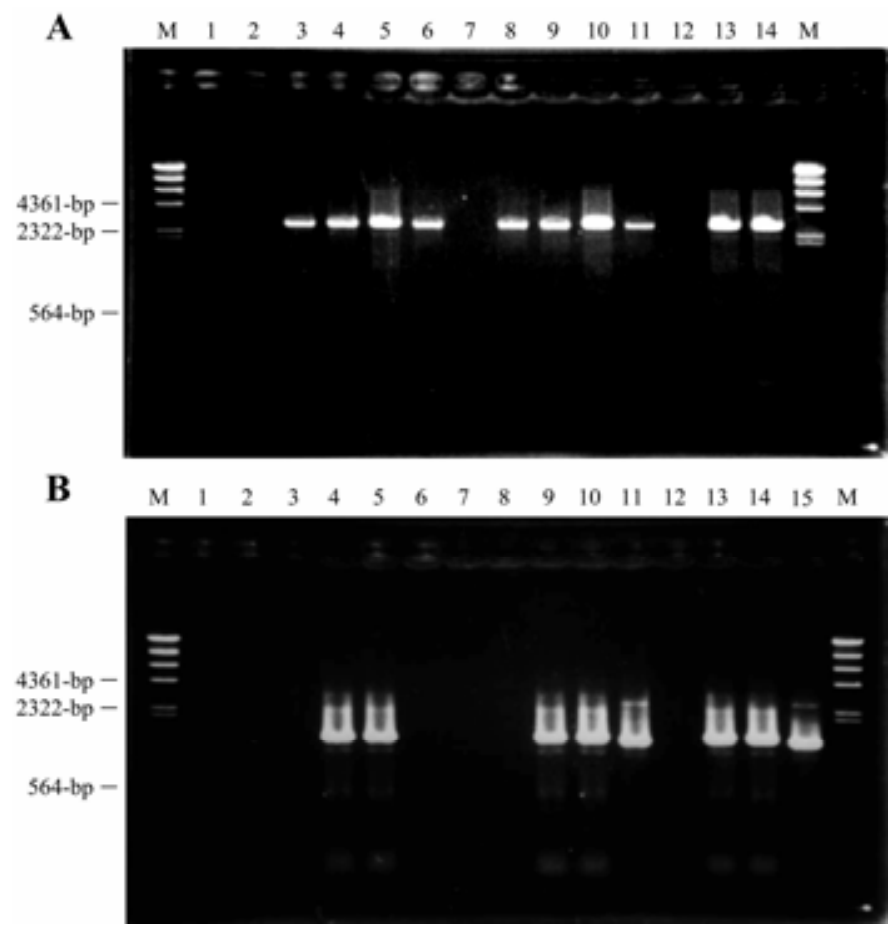

Fig. 7. Agarose gel electrophoresis of the polymerase chain reaction products obtained from agroinoculated tomato plants. Total DNA was extracted from the upper leaves of each tomato plant. $\mathrm{M}$ is a size marker consisting of $\lambda \mathrm{DNA}$ digested with HindIII. A, Plant samples: mock-agroinoculation (lane 1), DNA 301 alone (lane 2), Tomato leaf curl Java virus (ToLCJAV) alone (lane 3), ToLCJAV + DNAB01 (lane 4), ToLCJAV + DNAB02 (lane 5), ToLCJAV + recDNA (lane 6), DNA $\beta 01$ alone (lane 7), Ageratum yellow vein virus (AYVV-[Java]) alone (lane 8), AYVV-[Java] + DNA 301 (lane 9), AYVV[Java] + DNAß02 (lane 10), AYVV-[Java] + recDNA (lane 11), recDNA alone (lane 12), and ToLCJAV + AYVV-[Java] + DNA $\beta 01+$ DNA 302 + recDNA (lanes 13 and 14). The viral genomic full-length DNA products were amplified with the primer pairs ToXba1 and ToXba2 (lanes 1 to 6 and 13) and ToBam1 and ToBam2 (lanes 7 to 12 and 14). B, Plant samples: mock-agroinoculation (lane 1), DNA $\beta 01$ alone (lane 2), ToLCJAV alone (lane 3), ToLCJAV + DNA 301 (lane 4), ToLCJAV + DNAB02 (lane 5), ToLCJAV + recDNA (lane 6), DNA $\beta 01$ alone (lane 7), AYVV-[Java] alone (lane 8), AYVV-[Java] + DNAß01 (lane 9), AYVV-[Java] + DNAß02 (lane 10), AYVV-[Java] + recDNA (lane 11), recDNA alone (lane 12), and ToLCJAV + AYVV-[Java] + DNA $\beta 01$ + DNA $\beta 02$ + recDNA (lanes 13 to 15 ). The DNA $\beta 01$ and DNA $\beta 02$ full-length DNA fragments were amplified with the primer pairs StCla1 and StCla2 (lanes 1 to 10,13 , and 14) and the recDNA full-length DNA products were amplified with the primer pairs StBamH1 and StBamH2 (lanes 11, 12, and 15). plants in the presence of DNA $\beta 01$. Therefore, DNA $\beta 01$ appears to cause mild leaf curl symptoms that were observed in tomato plants, and may be defective, yet maintained in plants by ToLCJAV or AYVV-[Java].

DNA $\beta$ relies on its helper begomovirus for replication, movement within plants, and transmission between plants (27). DNA $\beta 01$ and DNA $\beta 02$ each contained an A-rich sequence. The A-rich region may have originated via sequence duplication to satisfy a size requirement for encapsidation and virus systemic movement (27). We showed that two DNA $\beta$ molecules (DNA $\beta 01$ and DNA $\beta 02)$ are replicated by two distinct monopartite begomoviruses (ToLCJAV and AYVV-[Java]). The iteron is the sequencespecific binding site for Rep $(2,7,13)$. The putative Rep-binding motifs present in ToLCJAV and AYVV-[Java] were not found in DNA $\beta 01$ and DNA $\beta 02$, but similar sequences are located upstream from the stem loop structure in these molecules. DNA $\beta 01$ and DNA $\beta 02$ do not contain the iterons of their respective helper begomoviruses, suggesting a more relaxed specificity for begomovirus Rep binding during their replication. DNA $\beta$ appears to be capable of being replicated by the Rep proteins from a diverse range of begomoviruses $(1,3,21,26,30)$.

The recDNA had the highest sequence identity with ToLCJAV, AYVV-[Java], DNA $\beta 01$, and DNA $\beta 02$. Therefore, recDNA has a chimeric genome, which arose via recombination between a begomovirus and DNA $\beta$. Further evidence for recombination in recDNA involving ToLCJAV, AYVV-[Java], DNA $\beta 01$, and DNA $\beta 02$ was supported by the statistical analysis using RDP. The recDNA replicated in the presence of AYVV-[Java], but not in the presence of ToLCJAV. The iteron sequence of recDNA was identical with that of AYVV-[Java]. A similar recombinant DNA component was found in AYVV-infected Ageratum conyzoides plants and Cotton leaf curl virus-infected cotton plants $(5,27)$. These results demonstrate the potential for the emergence of new satellitelike DNAs by recombination between previously existing begomoviruses and satellite DNA $\beta$ s.

Tan et al. (35) showed that AYVV could systemically infect tomato plants; however, the role of AYVV in tomato leaf curl in the field remained to be established. In the presence of DNA $\beta 02$, AYVV-[Java] caused tomato leaf curl disease in tomato plants, suggesting a possible role for this virus in this disease. The natural host of AYVV is A. conyzoides, a common weed, which often grows near tomato fields in Southeast Asia, including Indonesia, and frequently exhibits yellow vein symptoms. Thus, this weed could be a reservoir for viruses that cause tomato leaf curl disease. AYVV-[Java] alone induced upward leaf curling and vein swelling in $N$. benthamiana plants, but the symptoms changed to downward leaf curling in the presence of DNA $\beta 01$ or DNA $\beta 02$. Consistent with our results, a change from upward to downward leaf curling in the presence of DNA $\beta$ has been demonstrated experimentally for AYVV in $N$. benthamiana plants $(21$, 29,33). These results further support the hypothesis that DNA $\beta$ plays an important role in symptom induction.

We isolated two distinct begomovirus species from a single tomato plant with leaf curl symptoms. When two distinct begomoviruses infect a single plant in the field, the viruses may replicate simultaneously in the same cell, which is a prerequisite for recombination (23). A mixed infection is one of the prerequisites for developing new recombinant viruses or strains. The emergence of new begomovirus species in nature via recombination between existing species has been demonstrated $(12,17,30)$. We have isolated a new recombinant begomovirus that arose between ToLCJAV and AYVV-[Java] in A. conyzoides plants, which will be reported elsewhere.

\section{ACKNOWLEDGMENTS}

We thank B. Harrison (Scottish Crop Research Institute, Dundee, UK) for his valuable comments. This work was partly supported by Grants-in- 
Aid of the Academic Frontier Promotion Program from the Ministry of Education, Culture, Sports, Science and Technology of Japan.

\section{LITERATURE CITED}

1. Alberter, B., Rezaian, A. M., and Jeske, H. 2005. Replicative intermediates of ToLCV and its satellite DNAs. Virology 331:441-448.

2. Arguello-Astorga, G. R., Guevara-Gonzalez, R. G., Herrera-Estrella, L. R., and Rivera-Bustamante, R. F. 1994. Geminivirus replication origins have a group-specific organization of iterative elements: A model for replication. Virology 203:90-100.

3. Briddon, R. W., Bull, S. E., Amin, I., Idris, A. M., Mansoor, S., Bedford, I. D., Dhawan, P., Rishi, N., Siwatch, S. S., Abedel-Salam, A. M., Brown, J. K., Zafar, Y., and Markham, P. G. 2003. Diversity of DNA $\beta$, a satellite molecule associated with some monopartite begomoviruses. Virology $312: 106-121$

4. Briddon, R. W., Bull, S. E., Mansoor, S., Amin, I., and Markham, P. G. 2002. Universal primers for the PCR-mediated amplification of DNA $\beta$. Mol. Biotech. 20:315-318.

5. Briddon, R. W., Mansoor, S., Bedford, I. D., Pinner, M. S., Saunders, K., Stanley, J., Zafar, Y., Malik, K. A., and Markham, P. G. 2001. Identification of DNA components required for induction of cotton leaf curl disease. Virology 285:234-243.

6. Briddon, R. W., and Markham, P. G. 1994. Universal primers for the PCR amplification of dicot-infecting geminiviruses. Mol. Biotechnol. 1:202205.

7. Chatterii, A., Chatterji, U., Beachy, R. N., and Fauquet, C. M. 2000. Sequence parameters that determine specificity of binding of the replicationassociated protein to its cognate site in two strains of Tomato leaf curl virus-New Delhi. Virology 273:341-350.

8. Ditta, G., Stanfield, S., Corbin, D., and Helinski, D. R. 1980. Broad host range DNA cloning system for gram-negative bacteria: Construction of gene bank of Rhizobium meliloti. Proc. Natl. Acad. Sci. USA 77:73477351.

9. Dry, I. B., Rigden, J. E., Krake, L. R., Mullineaux, P. M., and Rezaian, M. A. 1993. Nucleotide sequence and genome organization of tomato leaf curl geminivirus. J. Gen. Virol. 74:147-151.

10. Engel, M., Fernandez, O., Jeske, H., and Frischmuth, T. 1998. Molecular characterization of a new whitefly-transmissible bipartite geminivirus infecting tomato in Panama. J. Gen. Virol. 79:2313-2317.

11. Fauquet, C. M., and Stanley, J. 2005. Revising the way we conceive and name viruses below the species level: A review of geminivirus taxonomy calls for new standardized isolate descriptors. Arch. Virol. 150:21512179

12. Galvao, R. M., Mariano, A. C., Luz, D. F., Alfenas, P. F., Andrade, E. C., Zerbini, F. M., Almeida, M. R., and Fontes, E. P. B. 2003. A naturally occurring recombinant DNA-A of a typical bipartite begomovirus does not require the cognate DNA-B to infect Nicotiana benthamiana systemically. J. Gen. Virol. 84:715-726.

13. Hanley-Bowdoin, L., Settlage, S. B., Orozco, B. M., Nagar, S., and Robertson, D. 2000. Geminivirus: Models for plant DNA replication, transcription, and cell cycle regulation. Crit. Rev. Biochem. Mol. Biol. $35: 105-140$.

14. Hoekema, A., Hirsch, P. R., Hooykaas, P. J. J., and Schilperoort, R. A. 1983. A binary plant vector strategy based on separation of the vir- and Tregion of the Agrobacterium tumefaciens Ti-plasmid. Nature 303:179-180.

15. Hong, Y. G., and Harrison, B. D. 1995. Nucleotide sequences from tomato leaf curl viruses from different countries: Evidence for three geographically separate branches in evolution of the coat protein of whiteflytransmitted geminiviruses. J. Gen. Virol. 76:2043-2049.

16. Jose, J., and Usha, R. 2003. Bhendi yellow vein mosaic disease in India is caused by association of a DNA $\beta$ satellite with a begomovirus. Virology 305:310-317.

17. Kitamura, K., Murayama, A., and Ikegami, M. 2004. Evidence for recombination among isolates of Tobacco leaf curl Japan virus and Honeysuckle yellow vein mosaic virus. Arch. Virol. 149:1221-1229.

18. Kon, T., Dolores, L. M., Bajet, N. B., Hase, S., Takahashi, H., and Ikegami, M. 2003. Molecular Characterization of a strain of Squash leaf curl China virus from the Philippines. J. Phytopathol. 151:535-539.

19. Kon, T., Dolores, L. M., Murayama, A., Bajet, N. B., Hase, S., Takahashi, H., and Ikegami, M. 2002. Genome organization of an infectious clone of Tomato leaf curl virus (Philippines), a new monopartite Begomovirus. J. Phytopathol. 150:587-591

20. Kumar, S., Tamura, K., and Nei, M. 2004. MEGA3: Integrated software for molecular evolutionary genetics analysis and sequence alignment. Brief Bioinform. 5:150-163.

21. Mansoor, S., Briddon, R.W., Zafar, Y., and Stanley, J. 2003. Geminivirus disease complexes: An emerging threat. Trends Plant Sci. 8:128-134.

22. Martin, D. P., Williamson, C., and Posada, D. 2005. RDP2: Recombination detection and analysis from sequence alignments. Bioinformatics 21:260-262.

23. Morilla, G., Krenz, B., Jeske, H., Bejarano, E. R., and Wege, C. 2004. Tete a tete of Tomato yellow leaf curl virus and Tomato yellow leaf curl Sardinia virus in single nuclei. J. Virol. 78:10715-10723.

24. Padidam, M., Beachy, R. N., and Fauquet, C. M. 1995. Tomato leaf curl geminivirus from India has a bipartite genome and coat protein is not essential for infectivity. J. Gen. Virol. 76:25-35.

25. Rojas, M. R., Gilbertson, R. L., Russell, D. R., and Maxwell, D. P. 1993. Use of degenerate primers in the polymerase chain reaction to detect whitefly-transmitted geminiviruses. Plant Dis. 77:340-347.

26. Saeed, M., Behjatnia, S. A., Mansoor, S., Zafar, Y., Hasnain, S., and Rezaian, M. A. 2005. A single complementary-sense transcript of a geminiviral DNA $\beta$ satellite is determinant of pathogenicity. Mol. Plant-Microbe Interact. 18:7-14.

27. Saunders, K., Bedford, I. D., Briddon, R. W., Markham, P. G., Wong, S. M., and Stanley, J. 2000. A unique virus complex causes Ageratum yellow vein disease. Proc. Natl. Acad. Sci. USA 97:6890-6895.

28. Saunders, K., Bedford, I. D., Yahara, T., and Stanley, J. 2003. The earliest recorded plant virus disease. Nature 422:831.

29. Saunders, K., Norman, A., Gucciardo, S., and Stanley, J. 2004. The DNA $\beta$ satellite component associated with ageratum yellow vein disease encodes an essential pathogenicity protein ( $\beta C 1)$. Virology 324:37-47.

30. Saunders, K., Salim, N., Mali, V. R., Malathi, V. G., Briddon, R., Markham, P. G., and Stanley, J. 2002. Characterisation of Sri Lankan cassava mosaic virus and Indian cassava mosaic virus: Evidence for acquisition of a DNA B component by a monopartite begomovirus. Virology 293:63-74.

31. Sharma, A., Murayama, A., Osaki, T., and Ikegami, M. 1998. Characterization of virus-specific DNA forms from tomato tissues infected by tobacco leaf curl virus: Evidence for a single genomic component producing defective DNA molecules. Plant Pathol. 47:787-793.

32. Shimizu, S., and Ikegami, M. 1999. Complete nucleotide sequence and the genome organization of tobacco leaf curl geminivirus from Japan. Microbiol. Immunol. 43:989-992.

33. Stanley, J. 2004. Subviral DNAs associated with geminivirus disease complexes. Vet. Microbiol. 98:121-129.

34. Sukamto, Kon, T., Hidayat, S. H., Ito, K., Hase, S., Takahashi, H., and Ikegami, M. 2005. Begomoviruses associated with leaf curl disease of tomato in Java, Indonesia. J. Phytopathol. 153:562-566.

35. Tan, P. H. N., Wong, S. M., Wu, M., Bedford, I. D., Saunders, K., and Stanley, J. 1995. Genome organization of ageratum yellow vein virus, a monopartite whitefly-transmitted geminivirus isolated from a common weed. J. Gen. Virol. 76:2915-2922.

36. Varma, A., and Malathi, V. G. 2003. Emerging geminivirus problems: A serious threat to crop production. Ann. Appl. Biol. 142:145-164.

37. Zhou, X., Xie, Y., Tao, X., Zhang, Z., Li, Z., and Fauquet, C. M. 2003. Characterization of DNA $\beta$ associated with begomoviruses in China and evidence for co-evolution with their cognate viral DNA-A. J. Gen. Virol. $84: 237-247$ 